\title{
Reliability research of eccentric freewheel mechanisms of friction type
}

\author{
Oleg Sharkov ${ }^{1, *}$, Sergey Koryagin ${ }^{1}$, and Nikolay Velikanov ${ }^{1}$ \\ ${ }^{1}$ Immanuel Kant Baltic Federal University, 236041 Kaliningrad, Russia
}

\begin{abstract}
The article contains a research of the influence of design parameters (material, the jamming angle) on operation reliability of eccentric friction-type freewheel mechanisms using calculated and experimental techniques. As the investigated factor, the lower limit of the confidence interval for the time between failures is adopted It is shown that the necessary reliability of the eccentric freewheel mechanisms is ensured when jamming angles are $8-10^{\circ}$ and when their elements are made of material $100 \mathrm{Cr} 6$. The reliability of such mechanisms is 1.7 times higher than of roller free-wheel mechanisms. The results of the research can be used when predicting the reliability of the mechanisms in the drives of machines.
\end{abstract}

\section{Introduction}

One of the crucial components used in machines and providing automatic connection and disconnection of their kinematic circuits is the freewheel mechanism [1-8].

Roller freewheel mechanisms are used the most widely in machines, which in some cases have the lack of reliability of work due to characteristic weaknesses: lack of durability and load capacity; large friction losses in the freewheeling period; high precision manufacture and installation of mechanism elements; considerable sensitivity to element deterioration [9-16].

Recommendations to increase the reliability of the roller freewheel mechanisms do not guarantee failure restoration, but they lead to substantial increases in the cost of their manufacture.

The general trend of increasing the resource and reliability of machines has led to the development of new designs of mechanisms - eccentric freewheel mechanisms [17].

The main advantages of eccentric freewheel mechanisms are: the compactness of the structure per unit of transmitted load; slight effect of wear on performance; relatively low requirements to the accuracy of manufacturing and assembly of the mechanism elements; low friction losses during freewheeling period.

Reliability of eccentric friction-type freewheel mechanisms is an integral indicator, which is influenced by various structural, technological and operational factors. Theoretical consideration of their influence is a complex task. Therefore, the evaluation of their reliability was carried out experimentally.

\footnotetext{
*Corresponding author: o_sharkov@,mail.ru
} 


\section{Experimental research of reliability}

\subsection{Experimental bench}

Investigation of the reliability of eccentric friction-type freewheel mechanisms was carried out on a special bench, which ensures the operation of the mechanisms under the most severe conditions.

The design of the experimental bench (Figure 1) includes: electric motor 1 (power 3.0 $\mathrm{kW}$, rated speed $1435 \mathrm{~min}^{-1}$ ); belt drive 2 (gear ratio $i=1.5$ ); the crank-rocker mechanism 3 , the output element of which is rigidly connected to the driving element of the freewheel mechanism. The outer casing of the mechanism is rigidly mounted in the replaceable casing 4 , which is connected to the electromagnetic brake 6 by means of a gear 5 (total gear ratio $i=1.0)$.

When the experimental bench works, for every turnover of crank a complete cycle of operation of eccentric freewheel mechanisms consisting of periods of jamming and jamming state, jamming out and freewheeling is executed.

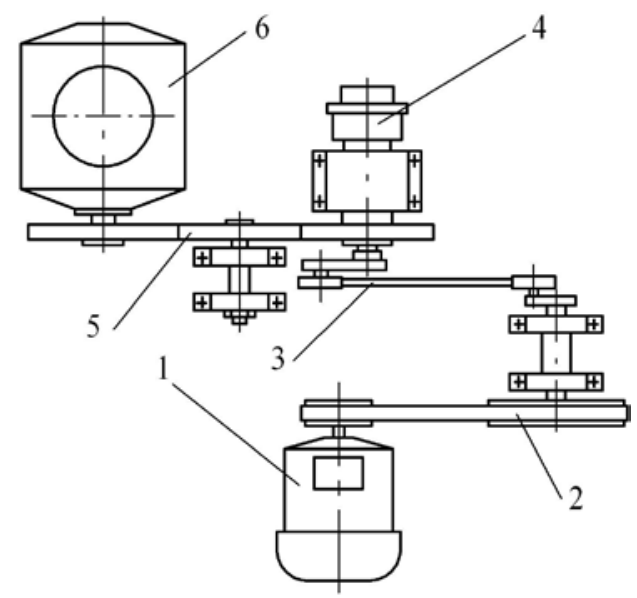

Fig. 1. Kinematic scheme of the experimental bench.

Turning on and off the freewheel mechanisms during bench operation occurs at the extreme positions of the rocker arm. Consequently, the dynamic loading of mechanisms will be greater than when working in the drives of machines.

\subsection{Experimental procedure}

As a criterion for reliability of eccentric freewheel mechanisms specified in the design, it is recommended to take the average time between failures [18-21]. To estimate it using the calculated and experimental approaches, it is necessary to determine the upper $t_{\mathrm{T}}$ and lower $t_{\mathrm{B}}$ limits of the confidence interval for the time between failures.

Since the freewheel mechanisms relate to the repairable constructions, the formulas for determining the upper $t_{\mathrm{T}}$ and lower $t_{\mathrm{B}}$ limits for the confidence interval can be written as

$$
t_{\mathrm{T}}=\frac{2 t_{\Sigma}}{\chi_{(1-\alpha) ; 2(n+1)}^{2}} \text {, }
$$




$$
t_{\mathrm{B}}=\frac{2 t_{\Sigma}}{\chi_{\alpha ; 2 n}^{2}},
$$

where $t_{\Sigma}$ - is the total test time of all specimens; $\chi_{(1-\alpha) ; 2(n+1)}^{2}$ and $\chi_{\alpha ; 2 n}^{2}$ - are the $\chi$ squared distribution with degrees of freedom $2(n+1)$ and $2 n ; n-$ is the total number of failures observed during the experiment $t_{\Sigma} ; \alpha-$ is the probability belief, $\alpha=0.9$.

A feature of the functioning of freewheel mechanisms is that the number of switching cycles for the same time can be different. Therefore, the limits of the confidence interval are conveniently defined as the number of cycles of the mechanism switching $N_{\mathrm{T}}$ and $N_{\mathrm{B}}$, which occurred respectively in time $t_{\mathrm{T}}$ and $t_{\mathrm{B}}$.

One of the following events was taken as a failure: slipping or hitting during turn-on and turn-off periods; noise and vibration during operation.

\subsection{Experimental specimens}

Experimental specimens of eccentric freewheel mechanisms (Table 1) series No. 1-6 were made with external arc protrusions $\beta=15^{\circ}$ on eccentric rings. The mechanisms of series No. 6 had rolling bodies (rollers) installed between the working surfaces of the eccentric and eccentric rings. Such a design solution makes it possible to reduce the angle of jamming. For comparison, Table 1 shows the freewheel roller mechanism (series No.7), whose reliability tests were carried out under similar conditions.

Table 1. The main parameters of prototype mechanisms.

\begin{tabular}{|c|c|c|l|}
\hline $\begin{array}{l}\text { Serial } \\
\text { number }\end{array}$ & $\begin{array}{l}\text { Diameter of casing } \\
D, \mathrm{~mm}\end{array}$ & Jamming angle $\alpha$ & Material \\
\hline 1 & 60 & $9^{\circ} \pm 25^{\prime}$ & $100 \mathrm{Cr} 6$ \\
\hline 2 & 60 & $9^{\circ} \pm 25^{\prime}$ & $14 \mathrm{NiCr} 10$ \\
\hline 3 & 60 & $9^{\circ} \pm 25^{\prime}$ & $20 \mathrm{MnCr} 5 \mathrm{G}$ \\
\hline 4 & 60 & $12^{\circ} \pm 25^{\prime}$ & $100 \mathrm{Cr} 6$ \\
\hline 5 & 60 & $5^{\circ} \pm 25^{\prime}$ & $100 \mathrm{Cr} 6$ \\
\hline 6 & 60 & $5^{\circ} \pm 25^{\prime}$ & $100 \mathrm{Cr} 6$ \\
\hline 7 & 107 & $7^{\circ} \pm 20^{\prime}$ & $100 \mathrm{Cr} 6$ \\
\hline
\end{tabular}

Each series included several prototypes of mechanisms with the same parameters. Mechanisms worked for 5-10 hours a day, with a switching frequency of $16 \mathrm{~Hz}$.

The reliability study of eccentric freewheel mechanisms included two stages. Initial break-in under conditions of reduced rated load $T=5-10 \mathrm{~N} \mathrm{~m}$ for $8-10$ hours. Then, each specimen was tested under an operating load $T=25 \mathrm{~N} \mathrm{~m}$ for a specified estimation time of 50 hours. During this period, the number of failures was fixed $n$ when the mechanisms work.

The reliability of the freewheel roller mechanisms was determined under similar conditions - rated load $T=100 \mathrm{~N} \mathrm{~m}$, switching frequency $5 \mathrm{~Hz}$, operating time of the mechanisms was $10 \ldots 15$ hours per day. 


\section{Experimental results and discussion}

To assess the reliability of eccentric freewheel mechanisms, the lower limit $N_{\mathrm{B}}$ of the confidence interval for mean time between failures (Figure 2) was adopted as a comparison criterion.

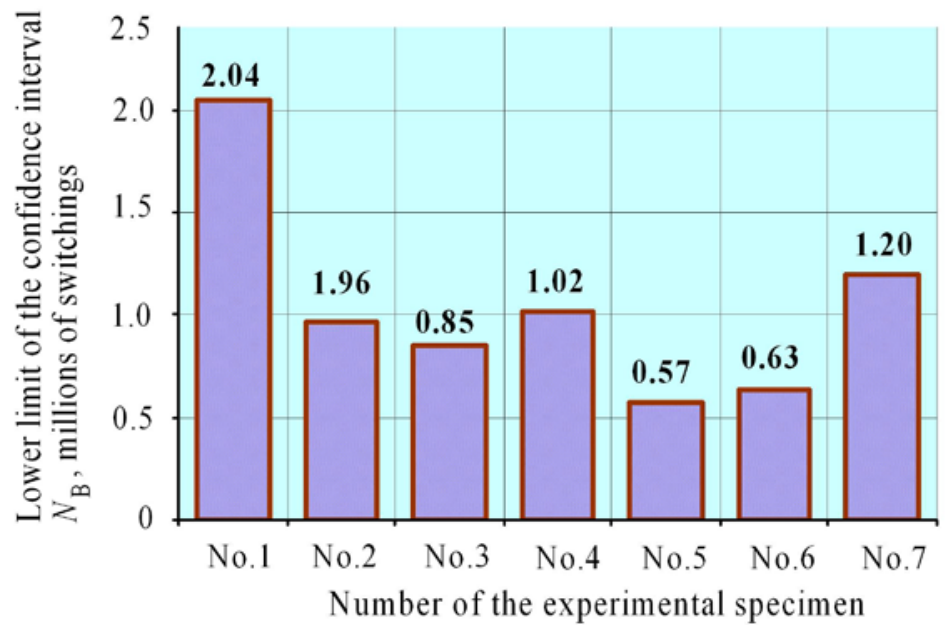

Fig. 2. Number of switching cycles, corresponding to the lower limit of the confidence interval for the time between failures.

Experimental specimens of eccentric freewheel mechanisms of the series No.1 showed high reliability of operation for the entire test period.

Experimental specimens of series No.2-3 after 30-40 hours of testing began to work with slipping. This happened because of the wear of their contacting surfaces due to insufficient wear resistance of $14 \mathrm{NiCr} 10$ and $20 \mathrm{MnCr} 5 \mathrm{G}$ steels under conditions of frequent switching.

For the prototypes of the mechanisms of the series No.4-5, after 20-30 hours of operation, their slipping and periodic non-jamming out became apparent. This is explained by the fact that the size of the jamming angles is correspondingly larger (specimen No.4) and less (specimen No.5) of the recommended $\alpha=8-10^{\circ}$.

The work of the prototype of the series No. 6 was accompanied by increased noise and vibration of the mechanism. After disassembly and inspection, it was established that the rollers do not rotate during operation, but are jammed between the working surfaces. As a result, dents and scuffs are formed on the raceways of the rolling bodies.

\section{Conclusion}

Experimentally proved that reliability of the eccentric friction-type freewheel mechanisms made of recommended $100 \mathrm{Cr} 6$ steel is 1.7 higher than of the roller ones. The mechanisms made of $14 \mathrm{NiCr} 10$ and $20 \mathrm{MnCr} 5 \mathrm{G}$ steels have roughly the same reliability, which is less than the roller ones in 1.25 and 1.41 times, respectively.

When the jamming angle is increased or decreased from the recommended value $\alpha=8-$ $10^{\circ}$ the reliability of the eccentric freewheel mechanisms decreases in comparison with the rollers in $1.17-2.10$ times. 
For reliable operation of eccentric freewheel mechanisms with rolling elements, high precision of manufacturing of elements is required. Their reliability is 1.9 times less than that of the roller ones.

\section{References}

1. W.C. Orthwein, Clutches and brakes: design and selection (New York, Marcel Dekker, 2004)

2. D. Aleksandrov, I. Penkov, Solid State Phenomena, 198, 226-231 (2013)

3. H. Ding, Jour. of Sound and Vibration, 353, 308-326 (2015)

4. S.V. Alyukov, Mathematical Models and Computer Simulations, 3(5), 661-669 ()

5. Y. Cao, H. Yan, Z. Liu, M. Zhang, International Jour. of Acoustics and Vibrations, 22(3), 395-402 (2017)

6. I. Taratorkin, V. Derzhanskii, A. Taratorkin, S. Kharitonov, SAE Technical Paper, 2014-01-2332 (2014)

7. S.K. Kang, H.K. In, K.J. Cho, International Jour. of Precision Engineering and Manufacturing, 13(8), 1487-1490 (2012)

8. P. Cherelle, V. Grosu, B. Vanderborght, D. Lefeber, L. Flynn, K. Junius, M. Moltedo, Robotics and Autonomous Systems, 91, 327-336 (2017)

9. O.V. Sharkov, S.I. Koryagin, N.L. Velikanov, IOP Conference Series: Materials Science and Engineering, 124, 012165 (2016)

10. K. Dürkopp, H.-J.Böhnke, W.Jorden, Wear, 162-164 (B), 985-989 (1993)

11. L-W. Chen, Y-C Chen, Proceedings of the Institution of Mechanical Engineers, Part D: Journal of Automobile Engineering, 222(9), 1647-1656 (2008)

12. I. Taratorkin, V. Derzhanskii, A. Taratorkin, Procedia Engineering, 150, 1368-13772 (2016)

13. M.N. Imran, M.B. Baharom, ARPN Journal of Engineering and Applied Sciences, 11(22), 13038-13041 (2016)

14. G.S. Mammano, E. Dragoni, Journal of Intelligent Material Systems and Structures, 27(14), 1976-1988 (2016)

15. S. Aliukov, A. Keller, A. Alyukov, SAE Technical Paper, 2015-01-2782 (2015)

16. K. Liua, E. Bambab, Tribology International, 38(2), 187-194 (2005)

17. O.V. Sharkov, A.V. Kalinin, Russian Engineering Research, 29(6), 551-554 (2009)

18. A.R. Wolfgang, M.L. Angel, C. Jan, Nuclear Instruments and Methods in Physics Research Section A: Accelerators, Spectrometers, Detectors and Associated Equipment, 551(2-3), 493-503 (2005)

19. K. Chwail, K.K. Choi, Journal of Mechanical Design, 130(12), 121401 (2008)

20. T. Nowakowski, M. Młyńczak, A. Jodejko-Pietruczuk, S. Werbińska-Wojciechowska, Safety and Reliability: Methodology and Applications (Boca Raton-Leiden, CRC Press, 2014)

21. I. Bazovsky, Reliability Theory and Practice (Mineola-New York, Courier Corporation, 2013) 